\title{
First case of Phthirus pubis and Demodex co-infestation of the eyelids: a case report
}

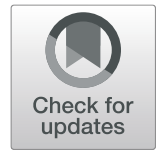

Yanan Huo ${ }^{1}$, Yanping $\mathrm{Mo}^{2}$, Xiuming Jin ${ }^{1}$, Xiaodan Huang ${ }^{1}$ and Wei Chen ${ }^{3^{*}}$ (D)

\begin{abstract}
Background: Phthirus pubis is an obligate parasite of human beings. Demodex spp. is a much more common parasite of human beings. However, P. pubis infestation accompanied by Demodex mite infestation in eye has not been reported.

Case presentation: We report the first case of Phthirus pubis and Demodex co-infestation on a 48-years-old woman. She presented to the hospital with itching and burning at her right eye for 2 weeks. Slit lamp examination revealed multiple nits and adults of P. pubis anchored to both upper and lower eyelashes. Eyelashes were trimmed, moxifloxacin eye ointment and fluorometholone eye drops were initiated daily. However, itching didn't improve after 2 weeks of treatment. Light microscopy examination of eyelashes revealed infestation with Demodex. The patient was treated with lid scrubs with 25\% tea tree oil daily for 4 weeks and was completely cured.
\end{abstract}

Conclusion: Our report shows the importance of an early and comprehensive diagnosis, because both phthiriasis palpebrarum and demodicosis can be confused with blepharitis.

Keywords: Phthirus pubis, Demodex, Co-infestation

\section{Background}

Phthirus pubis is an obligate parasite of human beings. It is mainly detectable in the hair of pubic, rectal and inguinal areas. The infestation of $P$. pubis in eyelid is rare, unilateral infestation is extremely rare [1]. Transmission of $P$. pubis to eyelashes may be manual from the infested body hair or during sexual contact. Indirect transmission through clothes or towels contaminated with nits is less frequent.

Demodex spp., on the other hand, is a much more common parasite of human beings. Out of many Demodex species, only Demodex folliculorum and Demodex brevis can parasitize in human eye. D. folliculorum is most commonly found in eyelash follicles, whereas $D$. brevis colonizes in the sebaceous and meibomian glands [2]. However, P. pubis infestation accompanied by

\footnotetext{
* Correspondence: wei_chen@zju.edu.cn

${ }^{3}$ Department of Medical Oncology, Tongde hospital of Zhejiang Province, NO, 234, Gucui Road, Hangzhou 310012, Zhejiang, China

Full list of author information is available at the end of the article
}

Demodex mite infestation in eye has not been reported. Here, we describe the first case of co-infestation by these two parasites.

\section{Case report}

A 48-year-old-woman presented to our hospital with unbearable itching and stinging with black secretion on her right eye for 2 weeks. She had no specific ocular, chronic or immune disease. Her best corrected visual acuity was 20/20. Slit lamp examination revealed over three hundred of translucent ovoid nits and over twenty live adult $P$. pubis firmly attached to the base and shaft of eyelashes. Dry blood and faeces appeared as granular and dark dots on nearby eyelids, which the patient considered as "black secretion" (Fig. 1). Lid margin vascular engorgement and mild hyperemia were observed in the conjunctiva. There was mild punctate defect on corneal epithelium. No nit, lice or any abnormal of ocular surface were observed in the left eye. The left cornea was clear and no vision decline. The patient was referred to 

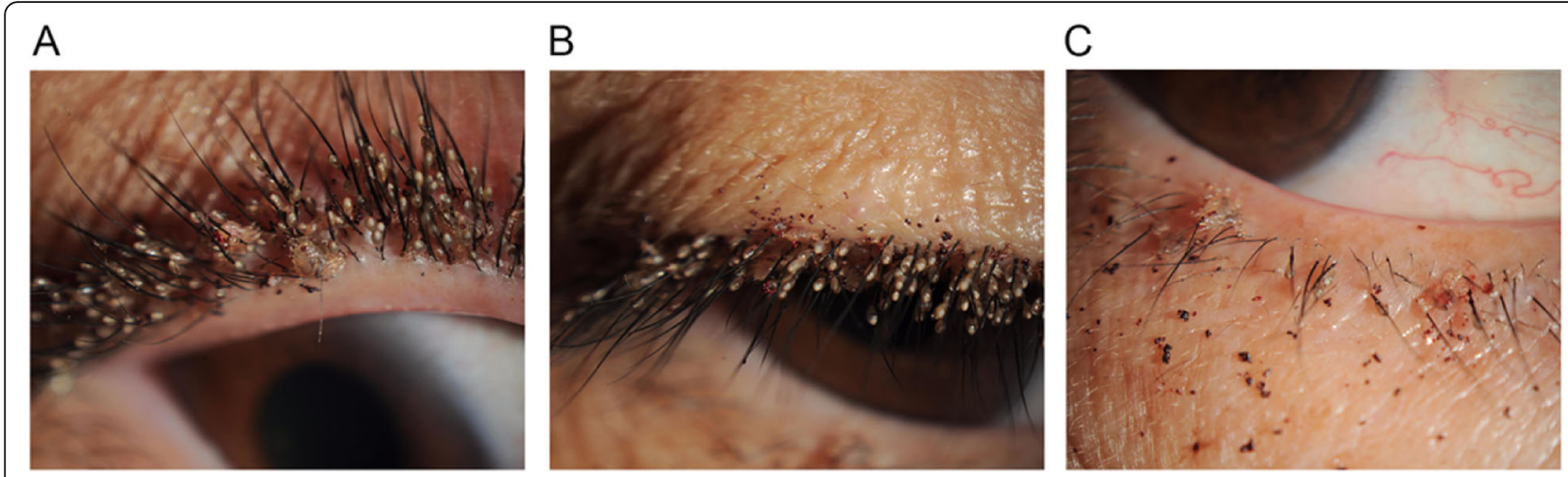

Fig. 1 Photos of her right eye shows multiple nits and lice on eyelashes of upper lid (a) (b) and lower lid (c), with dried blood on skin. Under slitlamp examination, adult lice adhere to eyelashes with crab-like bodies; the nits appear oval and translucent

dermatologist to detect potential phthiriasis lesions in other body parts. On dermatologic examination, lice were also detected in the pubic area. She had past history of sexual contacts with her husband. The search of sexually transmitted diseases was negative. Initial diagnosis of unilateral phthiriasis palpebrarum was made.

Mechanical removal of the lice and nits was attempted but failed as they were numerous. All eyelashes of the affected eye were trimmed with a scissors. Conjunctival sac was irrigated and lids margin was disinfected by compound iodine disinfectant cotton swab immediately and followed at weekly intervals. The patient was prescribed daily moxifloxacin eye ointment and fluorometholone eye drops four times a day for 2 weeks. The pubic hair was shaved and hexachlorocyclohexane cream was applied daily. The patient was advised to avoid close body contact and not to share clothing and towels.

After two-week's treatment, the patient returned to our hospital complaining with persistent itching of the right eye. The corneal epithelial punctate defect remained unchanged. There were no lice or nits observed on right eye. A co-infestation by Demodex was suspected. Three eyelashes from each eyelid of both eyes were epilated and examined with light microscopy.

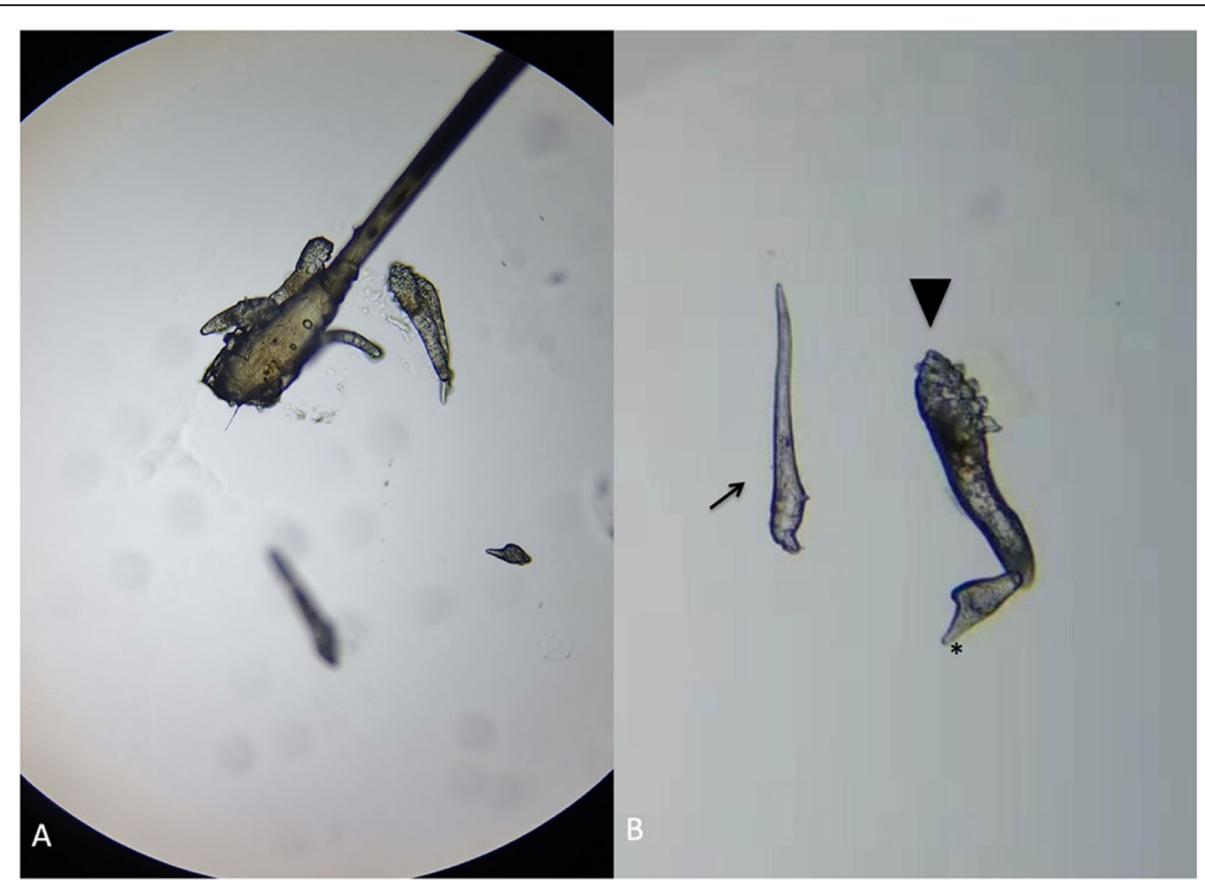

Fig. 2 Microscopic features of Demodex in the patient's right eye. a A group of Demodex and an egg were revealed with a lash follicle. b An egg (arrow), a larvae which had three pairs of poorly developed legs and a slender body (arrowhead), and an adult D. folliculorum with four pairs of well-developed legs $\left(^{*}\right)$ and a stumpier body 
Demodex detection and counting in epilated lashes were performed as proposed by Gao et al. [3]. A total of $14 D$. folliculorum was found in 6 lashes from the right eye (Fig. 2) and a total of 5 D. folliculorum was found in 6 lashes from the left eye. The diagnosis of demodicosis was confirmed. The lid margin around the root of the eyelashes were scrubbed by a sterile cotton-tipped applicator saturated with $25 \%$ tea tree oil daily and eyelids were heated with wet towel at about $40-45^{\circ} \mathrm{C}$ twice per day for 2 months. Clothing, pillow cases, and towels were recommended to be washed with hot water and then heat dried for up to 10 mins. The patient's symptoms relived, and the affected corneal was clear after two-week's treatment. The number of mites during an examination 1 month later reduced to 2 in the right eye and 0 in the left eye, and was reduced to 0 in both eye 2 months later. No recurrence was observed during 3 months of follow-up.

\section{Discussion and conclusions}

This is the first report of co-infestation by two different kinds of parasites in human eyelids, and also the most severe case of phthiriasis palpebrarum that has been reported in literature.

The infestation of phthiriasis palpebrarum happens mainly in people who live in crowded places or poor hygiene conditions. The infestation is usually transmitted by sexual activity because $P$. pubis is less mobile and cannot fly or jump from the initial located area to the eyes. Therefore, sexual abuse should be considered in children with $P$. pubis infestation [4]. There are multiple treatment options available like mechanical removal with forceps, pilocarpine hydrochloride, liquid Vaseline, moxifloxacin eye ointment, $1 \%$ mercury oxide, cryotherapy, argon laser, topical botulinum toxin application, 50\% tea tree oil, and $20 \%$ fluorescein eye drops [5-7]. In this case, we trimmed the eyelashes and treated patient with moxifloxacin eye ointment and fluorometholone eye drops. No lice or eggs were observed on the eyelashes.

Eye infestation by Demodex is much more common than P. pubis. Among a wide range of species, only D. folliculorum and D. brevis can parasitize the human eye. Demodex folliculorum lives in the lash follicle, whereas Demodex brevis lives solitarily and deeply in the sebaceous gland of the eyelash and the meibomian gland [2]. Hence, when eyelashes are sampled, the detection rate of $D$. folliculorum is much higher than that of $D$. brevis. Patients has cylindrical dandruff in eyelash roots should highly considered Demodex infestation $[3,8,9]$. However, in the presenting case, there was no typical cylindrical dandruff observed in both eyes. The previous treatment of topical eye ointment and weekly lid cleaning might covered the tracks of Demodex and its secretion on right eye. And the number of Demodex infestation on the left eye is too low to cause any symptoms.

Because Demodex can be found in healthy asymptomatic population, some authors have suggested that the relationship between symptoms and the number of Demodex should be considered at the same time. Three mites per three lashes should consider as Demodex infestation positive. If the related symptoms of Demodex infestation are serious, it can be diagnosed once the mite is detected [3, 810]. Many methods, including tea tree oil, $1 \%$ yellow mercury ointment, $2 \%$ topical metronidazole gel, $1 \%$ acaricide permethrin, and daily lid scrubbing and cleaning, can be used for eradicating ocular Demodex infestation [11-13]. We used $25 \%$ tea tree oil daily and heated the eyelids with wet towel at about $40-45^{\circ} \mathrm{C}$ twice per day for 2 months. The patient's symptoms relived, and the affected corneal was clear after two-week's treatment. No recurrence was observed during 3 months of follow-up.

Other authors have suggested that demodicosis may be associated with leukemia or immunodeficient patients with HIV-infection [14-16] or patients with end stage chronic renal failure [17]. However, the causal relationship between $P$. pubis infestation and Demodex infestation has not yet been studied.

In conclusion, here we report the first case of a severe infestation of P. pubis co-infested with Demodex in human eye. This report shows the importance of an early and comprehensive diagnosis, because both phthiriasis palpebrarum and demodicosis can be confused with blepharitis. In this case, the Demodex infestation of the right eye is much more severe than the left eye, and $P$. pubis only infested in the right eye. Whether the host's immune reactions by Demodex make it susceptible for $P$. pubis infestation is still unclear.

\section{Acknowledgements \\ Not applicable.}

\section{Authors' contributions}

HYN gathered and interpreted the patient data and was a major contributor in writing the manuscript. MYP, JXM, and HXD gathered and interpreted the patient imaging data and contributed in writing the manuscript. CW provided clinical guidance and contributed in writing the manuscript. All authors read and approved the final manuscript.

\section{Funding}

This work is supported by Zhejiang Natural Science Foundation (LY2OH120009) and National Natural Science Foundation of China (31751003).

\section{Availability of data and materials}

All data generated or analyzed during this study are included in this published article.

\section{Declarations}

Ethics approval and consent to participate

This research has obtained human research ethic approval from the Ethic Committee of the second Affiliated Hospital, School of medicine, Zhejiang university (2019-395). 


\section{Consent for publication}

Written consent was obtained from the patient for permission for

publication of her personal and clinical details along with identifying images to be published in this study.

\section{Competing interests}

The authors declare that they have no competing interests.

\section{Author details}

'Department of Ophthalmology, The Second Affiliated Hospital of Zhejiang University School of Medicine, Hangzhou 310009, China. ${ }^{2}$ Department of Ophthalmology, Huzhou Third Municipal Hospital, Huzhou 313000, China. ${ }^{3}$ Department of Medical Oncology, Tongde hospital of Zhejiang Province, NO, 234, Gucui Road, Hangzhou 310012, Zhejiang, China.

Received: 13 April 2020 Accepted: 22 February 2021

Published online: 06 March 2021

\section{References}

1. Panadero-Fontan R, Otranto D. Arthropods affecting the human eye. Vet Parasitol. 2015;208(1-2):84-93.

2. English FP, Nutting WB. Demodicosis of ophthalmic concern. Am J Ophthalmol. 1981;91(3):362-72.

3. Gao YY, Di Pascuale MA, Li W, Liu DT, Baradaran-Rafii A, Elizondo A, et al. High prevalence of Demodex in eyelashes with cylindrical dandruff. Invest Ophthalmol Vis Sci. 2005:46(9):3089-94.

4. Ryan MF. Phthiriasis palpebrarum infection: a concern for child abuse. J Emerg Med. 2014;46(6):e159-62.

5. Rundle PA, Hughes DS. Phthirus pubis infestation of the eyelids. $\mathrm{Br}$ J Ophthalmol. 1993;77(12):815-6.

6. Pinckney J 2nd, Cole P, Vadapalli SP, Rosen T. Phthiriasis palpebrarum: a common culprit with uncommon presentation. Dermatol Online J. 2008; 14(4):7.

7. Couch JM, Green WR, Hirst LW, de la Cruz ZC. Diagnosing and treating Phthirus pubis palpebrarum. Surv Ophthalmol. 1982;26(4):219-25.

8. Coston TO. Demodex folliculorum blepharitis. Trans Am Ophthalmol Soc. 1967;65:361-92.

9. Norn MS. Demodex folliculorum. Incidence and possible pathogenic role in the human eyelid. Acta Ophthalmol Suppl. 1970;108:7-85.

10. English FP. Demodex folliculorum and oedema of the eyelash. $\mathrm{Br} \mathrm{J}$ Ophthalmol. 1971;55(11):742-6.

11. Rodriguez AE, Ferrer C, Alio JL. Chronic blepharitis and Demodex. Arch Soc Esp Oftalmol. 2005;80(11):635-42.

12. Jansen $T$, Kastner $U$, Kreuter A, Altmeyer P. Rosacea-like demodicidosis associated with acquired immunodeficiency syndrome. Br J Dermatol. 2001; 144(1):139-42.

13. Murube J. Demodex hominis. Ocul Surf. 2015;13(3):181-6.

14. Damian $D$, Rogers M. Demodex infestation in a child with leukaemia: treatment with ivermectin and permethrin. Int J Dermatol. 2003;42(9):724-6.

15. Clyti E, Sayavong K, Chanthavisouk K. Demodecidosis in a patient infected by HIV: successful treatment with ivermectin. Ann Dermatol Venereol. 2005; 132(5):459-61.

16. Seyhan ME, Karincaoglu Y, Bayram N, Aycan O, Kuku I. Density of Demodex folliculorum in haematological malignancies. J Int Med Res. 2004;32(4):4115.

17. Karincaoglu Y, Esrefoglu Seyhan M, Bayram N, Aycan O, Taskapan H. Incidence of Demodex folliculorum in patients with end stage chronic renal failure. Ren Fail. 2005;27(5):495-9.

\section{Publisher's Note}

Springer Nature remains neutral with regard to jurisdictional claims in published maps and institutional affiliations.

Ready to submit your research? Choose BMC and benefit from:

- fast, convenient online submission

- thorough peer review by experienced researchers in your field

- rapid publication on acceptance

- support for research data, including large and complex data types

- gold Open Access which fosters wider collaboration and increased citations

- maximum visibility for your research: over $100 \mathrm{M}$ website views per year

At BMC, research is always in progress.

Learn more biomedcentral.com/submissions 